\title{
A Subtype-Specific Peptide-Based Enzyme Immunoassay for Detection of Antibodies to the G Protein of Human Respiratory Syncytial Virus Is More Sensitive than Routine Serological Tests
}

\author{
J. P. M. LANGEDIJK, ${ }^{1 *}$ A. H. BRANDENBURG,${ }^{2}$ W. G. J. MIDDEL,${ }^{1}$ AB OSTERHAUS, ${ }^{2}$ \\ R. H. MELOEN ${ }^{3}$ AND J. T. VAN OIRSCHOT ${ }^{1}$ \\ Department of Mammalian Virology ${ }^{1}$ and Department of Molecular Recognition, ${ }^{3}$ Institute for \\ Animal Science and Health 8200 AB, Lelystad, and Department of Virology, \\ Erasmus University Hospital, Rotterdam, ${ }^{2}$ The Netherlands
}

Received 30 September 1996/Returned for modification 25 November 1996/Accepted 26 March 1997

\begin{abstract}
Peptides deduced from the central conserved region (residues 158 to 189) of protein $G$ of human respiratory syncytial virus (HRSV) subtypes A and B were used as antigens in subtype-specific enzyme-linked immunosorbent assays (G-peptide ELISAs). These G-peptide ELISAs were compared with seven other serological assays to detect HRSV infection: ELISAs based on complete protein G, on fusion protein F, and on nucleoprotein N; a complement fixation assay; a virus neutralization test; and ELISAs for the detection of immunoglobulin A (IgA) or IgM antibodies specific for HRSV. In paired serum samples from patients with HRSV infection, more infections were diagnosed by the G-peptide ELISA (67\%) than by all other serological tests combined (48\%). Furthermore, for 16 of 18 patients (89\%), the G-peptide ELISAs were able to differentiate between antibodies against HRSV subtypes $A$ and $B$. This study shows that peptides corresponding to the central conserved region of the attachment protein G of HRSV can successfully be used as antigens in immunoassays. The G-peptide ELISA appeared to be more sensitive than conventional tests for the detection of HRSV antibody titer rises.
\end{abstract}

Human respiratory syncytial virus (HRSV) is the most important causative agent of bronchiolitis and pneumonia in young children. The virus is classified within the Pneumovirus genus of the Paramyxoviridae. Efficacious vaccines against respiratory syncytial virus (RSV) are not available. Because different antigenic subtypes are described for HRSV (6), it is important for epidemiological studies and vaccine developments to monitor the prevailing subtypes in a population. However, the available immunoassays (11) are based on whole virus or complete proteins that do not discriminate between subtypes of HRSV or between different RSV types.

The highly variable attachment protein $\mathrm{G}$ has limited homology between HRSV subtypes (53\% amino acid homology) (6). However, within the subtypes the amino acid homology is much larger: $>80 \%$ within HRSV subtype A (HRSV-A) strains (3) and $>90 \%$ within HRSV-B strains (10). Therefore, protein $G$ is a good candidate antigen for a discriminatory assay. We proposed that the ectodomain of protein $G$ contains a central, conserved, relatively hydrophobic region bounded by two hydrophilic, polymeric mucin-like regions (8). The central conserved region of HRSV, bovine RSV, and ovine RSV is a major antigenic site, and peptides corresponding to this region can be used as antigens in immunoassays (1, 7-9).

In a previous study, it was shown that conventional serology does not provide an adequate diagnostic tool for RSV infection in children younger than 6 months of age (2). In this study, the data obtained by these conventional serological tests were compared with those obtained by enzyme-linked immunosorbent assays (ELISAs) based on peptides corresponding to the central conserved region of HRSV-A and HRSV-B. Further-

\footnotetext{
* Corresponding author. Mailing address: Institute for Animal Science and Health, P.O. Box 65, 8200 AB, Lelystad, The Netherlands. Phone: 31-320-238216. Fax: 31-320-238050. E-mail: J.P.M.Langedijk @id.dlo.nl.
}

more, we demonstrated the applicability of the peptide-based ELISA for subtype-specific diagnosis.

\section{MATERIALS AND METHODS}

Peptide synthesis. Peptides corresponding to the central conserved regions of protein G (residues 158 to 189) of HRSV-A (12) and HRSV-B (6) were synthesized (Fig. 1). Peptide synthesis has been described previously (7).

Serum samples and specimens. Paired serum specimens from 33 different children (age, 0 to 6 months) with respiratory tract disease and suspected of having RSV infection were taken in the acute phase and 3 to 4 weeks later. Twenty-seven of these patients were confirmed to have an RSV infection by direct immunofluorescence of cells from nasopharyngeal washings, virus isolation on HEp-2 cells, and reverse transcription PCR (2). The RSV subtype was identified by using RSV subtype-specific monoclonal antibodies (MAbs; MAb 92-11C for HRSV-A and MAb 109 for HRSV-B; Chemicon) in an immunofluorescence assay with infected HEp-2 cells (2). Paired serum specimens from the 27 patients confirmed to be RSV positive were used to distinguish between antibody reactivity against the HRSV-A G peptide or the HRSV-B G peptide.

Paired serum specimens from 14 mothers of the 14 HRSV-A-infected children described above were taken at the same time that specimens were taken from their children. These sera were tested in the HRSV-A G-peptide ELISA to measure maternal antibody titers.

As a negative control, paired serum samples from six additional patients with acute infections caused by influenza virus type A, Chlamydia psittaci, and Mycoplasma pneumoniae, but not HRSV, were tested in the G-peptide ELISAs.

Two serum samples (samples 2369 and 2219) from two individuals (ages 2 and 3 years, respectively) positive for HRSV-specific antibodies collected during the 1993 to 1994 RSV epidemic were a kind gift of J. A. Melero, National Centre for Microbiology (Madrid, Spain). These two serum specimens were tested by Pepscan analysis.

Pepscan analysis. Peptides were synthesized on functionalized polyethylene rods and were tested for their reactivity with polyclonal antisera in an ELISA by established procedures (4). Forty-seven overlapping dodecapeptides of the ectodomain of the G protein of HRSV-A (12) between amino acids 153 and 211 were synthesized. This set of peptides includes all peptides corresponding to the central conserved region.

Neutralization test. Twofold dilutions (starting at 1:10) of test sera were incubated with $10050 \%$ tissue culture infective doses of HRSV-A2 for $1 \mathrm{~h}$ at $37^{\circ} \mathrm{C}$ in 96 -well tissue culture microtiter plates. HEp-2 cells were added to all wells, and the plates were incubated for 3 days at $37^{\circ} \mathrm{C}$ in $5 \% \mathrm{CO}_{2}$. The expression of viral antigen on the HEp- 2 cells was detected by ELISA with an Fprotein-specific MAb (MAb 92-11C; Chemicon) and antimouse horseradish peroxidase (HRPO; Dako, Glostrup, Denmark). Both incubations were for $1 \mathrm{~h}$ at $37^{\circ} \mathrm{C}$. Tetramethylbenzidine $-\mathrm{H}_{2} \mathrm{O}_{2}$ was used as the substrate. The reaction was 


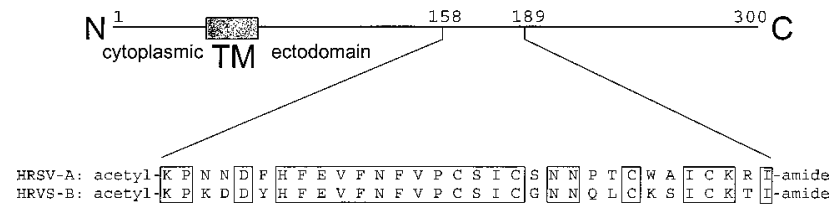

FIG. 1. Schematic representation of primary structure of HRSV-G. Shaded box, transmembrane region (TM). The primary structure of the synthesized peptides corresponding to the central conserved region of the ectodomain is shown.

stopped after $10 \mathrm{~min}$ with $0.2 \mathrm{M} \mathrm{H}_{2} \mathrm{SO}_{4}$. Absorption was read at $450 \mathrm{~nm}$. The percent virus neutralization was calculated by the following formula: (experimental OD - cell control OD)/(virus control OD - cell control OD) $\times 100$, where OD is optical density. The titer of the serum was defined as the dilution which gave $50 \%$ virus neutralization. Threefold titer rises were considered indicative of RSV infection.

Competition ELISAs. Competition ELISAs for RSV fusion protein F, attachment protein $\mathrm{G}$, and nucleoprotein $\mathrm{N}$ were performed as described previously (5). Partially purified RSV-A2 was coated $(2 \mu \mathrm{g} /$ well $)$ onto 96-well ELISA plates (Costar) overnight at $4^{\circ} \mathrm{C}$. Dilutions of $100 \mu \mathrm{l}$ of test sera (diluted 1:10 and 1:100) were incubated in the wells for $2 \mathrm{~h}$ at room temperature. A highly positive serum sample was used as the positive control (100\% inhibition), and ELISA buffer (phosphate-buffered saline, $3 \%$ extra $\mathrm{NaCl}, 0.1 \%$ bovine serum albumin, $0.1 \%$ milk powder, $5 \%$ normal rabbit serum, $1 \%$ fetal calf serum) was used as a negative control ( $0 \%$ inhibition). Subsequently, $50 \mu$ of the serum dilution was discarded and $50 \mu \mathrm{l}$ of anti-F (133/1H; Chemicon MAb 858-1), anti-G (131/2G; Chemicon MAb 858-2), or anti-N (23A3; Biosoft MAb 213-88) was added and the mixture was incubated for $1 \mathrm{~h}$ at $37^{\circ} \mathrm{C}$. Next, the wells were incubated with HRPO-conjugated rabbit anti-mouse (Dako) for $1 \mathrm{~h}$ at $37^{\circ} \mathrm{C}$. All dilutions were made in ELISA buffer. Tetramethylbenzidine- $\mathrm{H}_{2} \mathrm{O}_{2}$ was used as the substrate. The reaction was stopped after $10 \mathrm{~min}$ with $0.2 \mathrm{M} \mathrm{H}_{2} \mathrm{SO}_{4}$. Absorption was read at $450 \mathrm{~nm}$. Percent inhibition was calculated by the following formula: (experimental OD - OD for $100 \%$ inhibition)/OD for $0 \%$ inhibition - OD for $100 \%$ inhibition $) \times 100$. Threefold rises in the percentage of inhibition were considered indicative of RSV infection.

IgA and IgM capture ELISA. Anti-human immunoglobulin A (IgA) or IgM was coated onto the wells of 96-well ELISA plates (Costar) overnight at $4^{\circ} \mathrm{C}$. Test sera $(1: 100)$, partially purified RSV, $50 \mu \mathrm{l}$ of rabbit polyclonal anti-RSV serum (Dako), and HRPO-conjugated goat anti-rabbit (Dako) were each subsequently incubated for $1 \mathrm{~h}$ at $37^{\circ} \mathrm{C}$. Tetramethylbenzidine- $\mathrm{H}_{2} \mathrm{O}_{2}$ was used as the substrate. The reaction was stopped after 10 min with $0.2 \mathrm{M} \mathrm{H}_{2} \mathrm{SO}_{4}$. Absorption was read at $450 \mathrm{~nm}$. The cutoff value for positivity was more than two times the OD of a negative sample. A positive reaction was confirmed by immunofluorescence test.

Indirect G-peptide ELISA procedure. The G-peptide ELISA was performed as described previously (7), but with a modification in the coating procedure. One hundred fifty nanograms of crude oxidized peptide in $50 \mu \mathrm{l}$ of carbonate buffer (0.05 M; pH 9.6) was coated per well (high-binding-capacity flat-bottom microplate; Greiner) at $37^{\circ} \mathrm{C}$ overnight until all water was evaporated. Twofold dilutions of test sera (starting at 1:10) and anti-human HRPO (1:1,000; Dako) were incubated for $1 \mathrm{~h}$ at $37^{\circ} \mathrm{C}$ in ELISA buffer $\left(8.1 \mathrm{mM} \mathrm{Na}_{2} \mathrm{HPO}_{4}, 2.79 \mathrm{mM} \mathrm{KH}_{2} \mathrm{PO}_{4}\right.$, $0.5 \mathrm{M} \mathrm{NaCl}, 2.68 \mathrm{mM} \mathrm{KCl}, 1 \mathrm{mM}$ disodium EDTA, 0.05\% [vol/vol] Tween 80 [pH 7.2]) containing $4 \%$ horse serum. The substrate chromogen solution consisted of $10 \mathrm{mM}$ sodium phosphate buffer ( $\mathrm{pH} 6.8$ ), $0.1 \mathrm{mM}$ EDTA, $0.1 \%$ (wt/vol) 5-aminosalicylic acid, and freshly added $0.005 \%$ (vol $/ \mathrm{vol}) \mathrm{H}_{2} \mathrm{O}_{2}$. Incubation with substrate solution was performed overnight at $4^{\circ} \mathrm{C}$. Color development was measured at $450 \mathrm{~nm}$ (Titertek Multiscan). Absorbance values higher than two times the average background value of test serum in control wells without peptide were considered positive. Fourfold titer rises or seroconversion $(<10$ to $\geq 20)$ in paired serum specimens are designated defined titer rises and were considered indicative of RSV infection.

\section{RESULTS}

The reactivity of a panel of paired serum specimens was tested in the HRSV-A and HRSV-B peptide ELISAs described in Materials and Methods (Table 1). To evaluate the HRSV specificity of the ELISAs, the reactivities of paired serum specimens which showed antibody titer rises against other agents were tested in both peptide ELISAs (Table 2). No titer rises were observed for the negative controls.

In Table 1, titer rises may be missed because of the high titer of the acute-phase serum. Because a high titer in the acutephase serum may be due to maternal antibodies, the paired serum specimens from some of the mothers were tested in the HRSV-A peptide ELISA (Table 3). No significant association
TABLE 1. Antibody titers in paired serum specimens from patients with a respiratory infection determined by both G-peptide ELISAs

\begin{tabular}{|c|c|c|c|}
\hline \multirow{2}{*}{ Patient no. } & \multicolumn{3}{|c|}{ Titer by the following G-peptide ELISA ${ }^{a}$ : } \\
\hline & RSV type & Peptide A & Peptide B \\
\hline 2 & A & $<10,40$ & $<10,<10$ \\
\hline 6 & A & 10,80 & $<10,<10$ \\
\hline 9 & A & 20,160 & $<10,<10$ \\
\hline 11 & A & 80,40 & $<10,<10$ \\
\hline 17 & A & 10,160 & $<20,<10$ \\
\hline 18 & A & 10,10 & $<10,<10$ \\
\hline 19 & A & 10,20 & $<10,<10$ \\
\hline 26 & A & $<10,40$ & $<10,<10$ \\
\hline 27 & A & 10,10 & $<10,<10$ \\
\hline 28 & A & $<10,40$ & $<10,<10$ \\
\hline 30 & A & $<10,20$ & $<10,<10$ \\
\hline 36 & A & $<10,640$ & $<10,<10$ \\
\hline 37 & A & $<10,320$ & $<10,<10$ \\
\hline 41 & A & 40,80 & $<10,<10$ \\
\hline 7 & B & $<10,20$ & $10,<10$ \\
\hline 8 & B & $10,<10$ & $<10,20$ \\
\hline 10 & B & $40,<10$ & $<10,40$ \\
\hline 13 & B & $20,<10$ & $<10,20$ \\
\hline 15 & B & $<10,10$ & $<10,<10$ \\
\hline 21 & B & $10,<10$ & $<10,40$ \\
\hline 23 & B & 10,10 & $<10,80$ \\
\hline 24 & B & 10,20 & $<10,10$ \\
\hline 25 & B & $10,<10$ & $<10,<10$ \\
\hline 35 & B & $10,<10$ & $<10,40$ \\
\hline 38 & B & 10,40 & $<10,10$ \\
\hline 39 & B & 10,10 & $<10,<10$ \\
\hline 40 & B & $<10,<10$ & $<10,20$ \\
\hline 1 & & $<10,<10$ & $<10,<10$ \\
\hline 4 & & $<10,40$ & $<10,<10$ \\
\hline 5 & & $<10,<10$ & $<10,<10$ \\
\hline 12 & & $<10,<10$ & $<10,<10$ \\
\hline 14 & & $<10,<10$ & $<10,<10$ \\
\hline 29 & & $<10,<10$ & $<10,<10$ \\
\hline
\end{tabular}

${ }^{a}$ The pairs of values in each column are for the paired sera from each patient. Titers in boldface represent defined titer rises.

was found for the maternal antibody titer and the corresponding titer in the acute-phase serum from the child $(P=0.13$, according to Fisher's exact test for two-way tables).

\section{DISCUSSION}

Detection of RSV infection in young children by conventional serological tests as described in a previous study (2) was

TABLE 2. Antibody titers in paired serum specimens from patients with a non-RSV infection determined by both G-peptide ELISAs ${ }^{a}$

\begin{tabular}{llccc}
\hline Patient & \multicolumn{1}{c}{$\begin{array}{c}\text { Non-HRSV } \\
\text { infection }\end{array}$} & $\begin{array}{c}\text { Non-HRSV } \\
\text { titer rise }\end{array}$ & \multicolumn{2}{c}{$\begin{array}{c}\text { Titer by the following } \\
\text { G-peptide ELISA: }\end{array}$} \\
\cline { 4 - 5 } & & 7,32 & 320,160 & 80,80 \\
\hline WA & Influenza virus type A & $<16,>64$ & 80,80 & $<10,<10$ \\
$\mathrm{~B}$ & C. psittaci & $7,>96$ & 40,20 & $10,<10$ \\
$\mathrm{G}$ & Influenza virus type A & 12,80 & 80,80 & 10,10 \\
$\mathrm{WB}$ & Influenza virus type A & $<16,32$ & 20,10 & $10,<10$ \\
$\mathrm{H}$ & M. pneumoniae & $<16,64$ & 640,320 & 20,20 \\
$\mathrm{~V}$ & M. pneumoniae & &
\end{tabular}

${ }^{a}$ The pairs of values in the last three columns are for the paired sera from each patient. 
TABLE 3. Antibody titers in paired serum specimens from mothers of patients with a respiratory infection by HRSV-A G-peptide ELISA

\begin{tabular}{ll} 
Mother & $\begin{array}{c}\text { Titer by } \\
\text { G-peptide ELISA } \\
\text { for peptide } A^{a}\end{array}$ \\
\hline 28 & \\
30 &
\end{tabular}

${ }^{a}$ The pairs of values are for the paired sera from each mother.

${ }^{b}$ Numbers in boldface represent mothers of children with a high acute-phase serum titer.

${ }^{c}$ - , serum was not available. compared with detection of RSV infection with the aid of novel G-peptide ELISAs (Table 4). In summary, 18 of 27, 6 of 27,0 of 27,0 of 27,6 of 27,5 of 27,0 of 27 , and 0 of 27 specimens scored positive in the G-peptide ELISA, protein-G ELISA, protein-F ELISA, protein-N ELISA, neutralization test, IgA ELISA, IgM ELISA, and complement fixation test, respectively (Table 4). The G-peptide ELISAs performed even better (18 of 27 specimens) than the combination of all other serological tests (12 of 27 specimens) (Table 4). Statistical analyses of the sensitivity of different assays are presented in Table 5. In 6 of the 33 patients, no virus or antigen could be detected (see Materials and Methods) (2). In paired serum specimens from these six patients not confirmed to be infected with RSV, one RSV-specific antibody titer rise was detected in the neutralization test (Table 4). In another patient not confirmed to be infected with RSV, a titer rise was observed in the HRSV-A G-peptide ELISA. The latter two findings may suggest that these sera reacted aspecifically. However, it may also be possible that the virus or antigen detection test was false negative or that the virus was already cleared from the body before the patients entered the hospital. No titer rises were detected in paired serum specimens from patients infected with other agents (Table 2).

The HRSV-A and HRSV-B G-peptide ELISAs are selective

TABLE 4. Detection of HRSV infection by several serological tests

\begin{tabular}{|c|c|c|c|c|c|c|c|c|c|c|}
\hline $\begin{array}{l}\text { Patient } \\
\text { no. }\end{array}$ & $\begin{array}{l}\text { RSV } \\
\text { type }\end{array}$ & $\begin{array}{l}\text { Peptide-A } \\
\text { ELISA }\end{array}$ & $\begin{array}{c}\text { Peptide-B } \\
\text { ELISA }\end{array}$ & $\begin{array}{l}\text { Protein-G } \\
\text { ELISA }^{a}\end{array}$ & $\begin{array}{l}\text { Protein-F } \\
\text { ELISA }^{a}\end{array}$ & $\begin{array}{l}\text { Protein-N } \\
\text { ELISA }^{a}\end{array}$ & $\begin{array}{l}\text { Neutraliza- } \\
\text { tion test }^{a}\end{array}$ & $\begin{array}{c}\text { IgA } \\
\text { ELISA }^{a}\end{array}$ & $\begin{array}{c}\text { IgM } \\
\text { ELISA }^{a}\end{array}$ & $\begin{array}{l}\text { Complement } \\
\text { fixation test }{ }^{a}\end{array}$ \\
\hline 2 & A & $+^{b}$ & $-^{c}$ & + & - & - & + & - & - & - \\
\hline 6 & A & + & - & - & - & - & - & - & - & - \\
\hline 9 & A & + & - & + & - & - & + & - & - & - \\
\hline 11 & A & - & - & - & - & - & - & - & - & - \\
\hline 17 & A & + & - & - & - & - & - & + & - & - \\
\hline 18 & A & - & - & - & - & - & - & + & - & - \\
\hline 19 & A & - & - & - & - & - & - & - & - & - \\
\hline 26 & A & + & - & - & - & - & - & - & - & - \\
\hline 27 & A & - & - & - & - & - & - & + & - & - \\
\hline 28 & A & + & - & + & - & - & - & - & - & - \\
\hline 30 & A & + & - & + & - & - & - & + & - & - \\
\hline 36 & A & + & - & + & - & - & + & - & - & - \\
\hline 37 & A & + & - & - & - & - & + & - & - & - \\
\hline 41 & A & - & - & - & - & - & - & - & - & - \\
\hline 7 & B & + & - & - & - & - & - & - & - & - \\
\hline 8 & B & - & + & - & - & - & - & - & - & - \\
\hline 10 & B & - & + & + & - & - & - & - & - & - \\
\hline 13 & B & - & + & - & - & - & - & - & - & - \\
\hline 15 & B & - & - & - & - & - & - & - & - & - \\
\hline 21 & B & - & + & - & - & - & + & + & - & - \\
\hline 23 & B & - & + & - & - & - & - & - & - & - \\
\hline 24 & B & - & - & - & - & - & + & - & - & - \\
\hline 25 & B & - & - & - & - & - & - & - & - & - \\
\hline 35 & B & - & + & - & - & - & - & - & - & - \\
\hline 38 & B & + & - & - & - & - & - & - & - & - \\
\hline 39 & B & - & - & - & - & - & - & - & - & - \\
\hline 40 & B & - & + & - & - & - & - & - & - & - \\
\hline $1^{d}$ & & - & - & - & - & - & + & - & - & - \\
\hline $4^{d}$ & & + & - & - & - & - & - & - & - & - \\
\hline $5^{d}$ & & - & - & - & - & - & - & - & - & - \\
\hline $12^{d}$ & & - & - & - & - & - & - & - & - & - \\
\hline $14^{d}$ & & - & - & - & - & - & - & - & - & - \\
\hline $29^{d}$ & & - & - & - & - & - & - & - & - & - \\
\hline
\end{tabular}

${ }^{a}$ Data obtained from Brandenburg et al. (2).

${ }^{b}+$, defined antibody titer rise indicative of HRSV infection.

${ }^{c}-$, no defined antibody titer rise.

${ }^{d}$ Paired sera from patients in which no virus or antigen could be detected. 
TABLE 5. Two-sided 95\% confidence intervals for different assay

\begin{tabular}{l} 
Serological test \\
Interval $(\%)$ \\
\hline G-peptide ELISA \\
Protein-G ELISA \\
Protein-F ELISA \\
Protein-N ELISA \\
Neutralization test \\
IgA ELISA
\end{tabular}

for the subtype-specific detection of HRSV infection. Patients infected with HRSV-A were only diagnosed positive by the HRSV-A G-peptide ELISA. Patients infected with HRSV-B were diagnosed positive seven times by the HRSV-B G-peptide ELISA and twice by the HRSV-A G-peptide ELISA. The reactivities of two paired serum specimens from supposedly HRSV-B-infected children in the HRSV-A peptide ELISA is puzzling. Several explanations can be conceived for this observation. First, the MAb-based subtype was wrong. This explanation seems unlikely because the MAb-based subtype was confirmed by subtype-specific PCR. Second, the child was infected with both virus types, and an antibody response was developed only against subtype A. Third, the cross-reactive sera are directed against an epitope conserved in HRSV subtypes $\mathrm{A}$ and $\mathrm{B}$, and this epitope is better exposed in the HRSV-A peptide. We do have some examples of sera that bind to a conserved epitope in the N-terminal part of the HRSV-A peptide (Fig. 2). Pepscan analysis showed two examples of human sera that bound to five successive overlapping peptides which shared the amino acid sequence DFHFEVFN (amino acids 162 to 169). This sequence is conserved in HRSV-B except for the mutation of $\mathrm{F}$ to $\mathrm{Y}$ at position 163 (Fig. 1). It is possible that this relatively conserved epitope is responsible for cross-reactivity in the peptide ELISA. Therefore, a smaller peptide which only contains the more variable C-terminal part of the central conserved region would seem more useful for subtype-specific diagnosis. However, a 16-residue peptide ELISA based on the shorter C-terminal peptide (residues 174 to 189 ) without the conserved part was significantly less sensitive than the 32-residue peptide used in the assays (7). Perhaps investigators will be able to find new immunodominant peptides which can be combined with the 16-residue peptide to develop an ELISA that is $100 \%$ subtype specific. However, such peptides, derived from the highly variable mucin-like regions, are probably strain specific and not completely subtype specific.

In the sera of nine patients we did not detect a defined titer rise in the HRSV-A or the HRSV-B peptide ELISA. In the case of patients 11 and 41, this may be due to the high titer in the first serum sample (Table 1). Perhaps the first sampling date was too late for these two patients. We presumed that the high titer of the acute-phase serum was probably not caused by maternal antibodies since no evident association between the antibody titer in the mother's serum and the titer in the acutephase serum from the child was observed. The inability to diagnose an RSV infection in the seven other patients may be explained by a low or no antibody response in these children. The patients were young or prematurely born children and therefore may not have been fully immunocompetent. Two of the five serum samples that did not react in the peptide ELISA gave a positive response in the IgA ELISA only. Therefore, the sensitivity of the peptide ELISA may be increased when the reactivities of $\operatorname{IgA}$ antibodies are also tested.
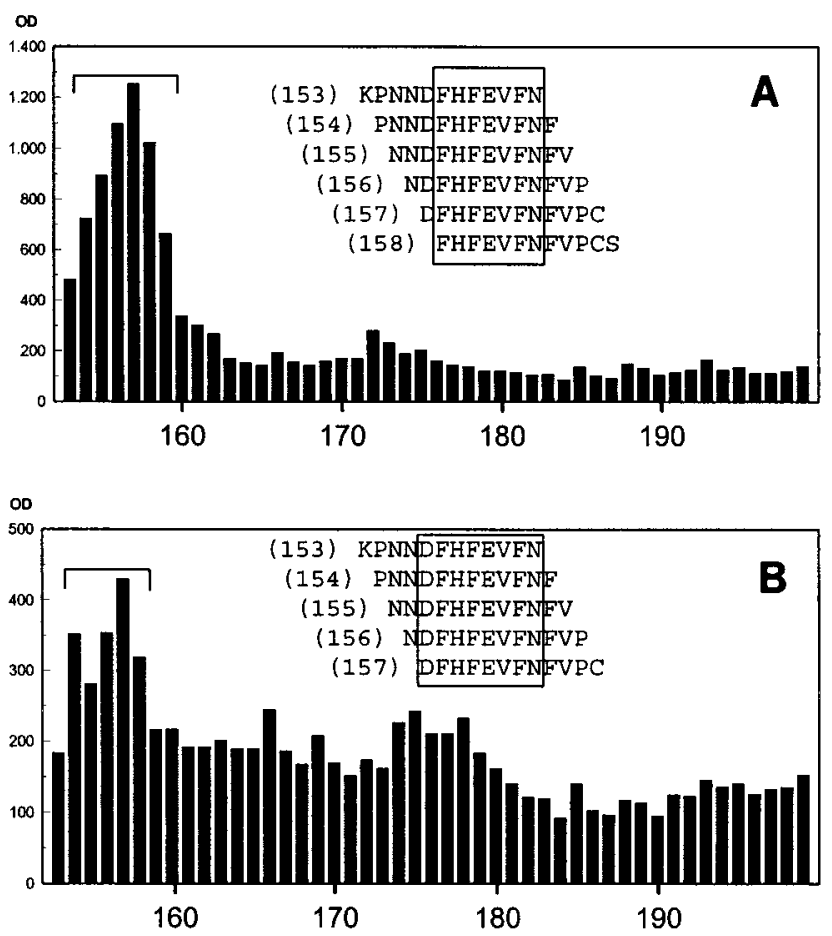

FIG. 2. Reactivities of two positive control serum samples from infected children with overlapping peptides of the ectodomain of HRSV-G (12) between amino acids 153 and 211. (a) Reactivity of serum sample 2369 (dilution, 1:100). (b) Reactivity of serum sample 2219 (dilution, 1:100). Numbers on the horizontal axis correspond to the N-terminal amino acid of the 12-residue peptide. Absorbances at $405 \mathrm{~nm}$ obtained with each peptide in an ELISA are plotted vertically. Reactive peptides are listed in the graph, and the shared amino acids are boxed.

The complete G-protein ELISA uses HRSV-A protein G as the antigen. Fewer infections were detected by the ELISA based on the complete HRSV-A protein G than by the ELISA based on the HRSV-A G peptide. The higher sensitivity of the HRSV-A G-peptide ELISA compared with that of the complete protein-G ELISA may be explained partly by the different format of the assays and the definition of a defined titer rise. Important advantages of a peptide-based ELISA are the low cost, the ease of production and the unvarying quality of the peptide, and the coated microtiter plates. Furthermore, the peptide-based RSV ELISA described in this study performs better than conventional serological assays with sera from these young children. Compared with other immunoassays, the peptide-based ELISA is a sensitive immunoassay for the detection of RSV infections. Despite considerable amino acid sequence homology between the central conserved regions of HRSV-A and HRSV-B proteins G, the peptide ELISA is specific for RSV subtype A and selective for subtype B-specific antibody detection.

\section{ACKNOWLEDGMENTS}

We thank J. A. Melero for providing us with human sera and Drohpati Parohi and Wouter Puijk for technical assistance.

\section{REFERENCES}

1. Åkerlind-Stopner, B., G. Utter, M. A. Mufson, C. Orvell, R. A. Lerner, and E. Norrby. 1990. Subgroup-specific antigenic site in the G protein of respiratory syncytial virus forms a disulfide-bonded loop. J. Virol. 64:5143-5148. 2. Brandenburg, A. H., J. Groen, H. A. van Steensel-Moll, E. C. J. Claas, P. H. Rothbarth, H. J. Neijens, A. D. M. E. Osterhaus. Respiratory syncytial virus specific antibodies in infants under six months of age: limited serological response upon infection. J. Med. Virol., in press. 
3. Cane, P. A., D. A. Matthews, and C. R. Pringle. 1991. Identification of variable domains of the attachment $(\mathrm{G})$ protein of subgroup A respiratory syncytial viruses. J. Gen. Virol. 7:2091-2096.

4. Geysen, H. M., R. H. Meloen, and S. J. Barteling. 1984. Use of synthetic peptide synthesis to probe viral antigens for epitopes to a resolution of a single amino acid. Proc. Natl. Acad. Sci. USA 81:3998-4002.

5. Groen, J., G. van den Groen. 1989. Comparison of immunofluorescence and enzyme-linked immunosorbent assays for the serology of Hantaan virus infections. J. Virol. Meth. 23:195-203.

6. Johnson, P. R., M. K. Spriggs, R. A. Olmsted, and P. L. Collins. 1987. The $\mathrm{G}$ glycoprotein of human respiratory syncytial viruses of subgroups A and B: extensive sequence divergence between antigenically related proteins. Proc. Natl. Acad. Sci. USA 84:5625.

7. Langedijk, J. P. M., W. G. J. Middel, W. M. M. Schaaper, R. H. Meloen, J. A Kramps, A. H. Brandenburg, and J. T. Van Oirschot. 1996. Type-specific serologic diagnosis of respiratory syncytial virus infection, based on a synthetic peptide of the attachment protein G. J. Immunol. Methods 193:157-166.
8. Langedijk, J. P. M., W. M. M. Schaaper, R. H. Meloen, and J. T. Van Oirschot. 1996. Proposed three-dimensional model for attachment protein G of respiratory syncytial virus. J. Gen. Virol. 77:1249-1257.

9. Norrby, E., M. A. Mufson, H. Alexander, R. A. Houghten, and R. A. Lerner. 1987. Site-directed serology with synthetic peptides representing the large glycoprotein $\mathrm{G}$ of respiratory syncytial virus. Proc. Natl. Acad. Sci. USA 84:6572.

10. Sullender, W. M., M. A. Mufson, L. J. Anderson, and G. W. Wertz. 1991 Genetic diversity of the attachment protein of subgroup B respiratory syncytial viruses. J. Virol. 65:5425-5434

11. Welliver, R. C. 1988. Detection, pathogenesis, and therapy of respiratory syncytial virus infections. Clin. Microbiol. Rev. 1:27-39.

12. Wertz, G. W., P. L. Collins, Y. Huang, C. Gruber, S. Levine, and L. A. Ball. 1985. Nucleotide sequence of the G protein of human respiratory syncytial virus reveals an unusual type of viral membrane protein. Proc. Natl. Acad. Sci. USA 82:4075. 